\section{Postoperative hypoxaemia in children undergoing elective palatoplasty}

To the Editor:

We would like to report the incidence, severity and duration of early postoperative hypoxaemia in 130 infants and children, ASA grade I, aged 8 mo to $14 \mathrm{yr}$, scheduled for elective palatoplasty. The $\mathrm{SpO}_{2}$ was measured continuously with a Datex pulse oximeter in the PAR and was recorded at $0,5,10,15,20,30,40,50$, 60,120 and $180 \mathrm{~min}$ after arrival. Children were graded as 1) nonhypoxaenic $\left.\left(\mathrm{SpO}_{2} 91 \%\right) ; 2\right)$ hypoxaemic $\left(\mathrm{SpO}_{2}=86-90 \%\right)$ or 3$)$ severely hypoxaemic $\left(\mathrm{SpO}_{2}\right.$ $85 \%) .{ }^{1}$ The modified Aldrete's scoring system ${ }^{2}$ was used to evaluate recovery from anaesthesia.

Compared with preoperative $\mathrm{SpO}_{2}$ levels, mean postoperative $\mathrm{SpO}_{2}$ of all patients breathing room air declined in the early postoperative period but gradually increased. The incidence of hypoxaemia and severe hypoxaemia on arrival the PAR, $31.5 \%$ and $10.8 \%$ respectively, gradually improved (Table). The incidence of early postoperative hypoxaemia in children undergoing Von Langenbeck palatoplasty was less $(33.9 \%$ vs $61.9 \%, P<0.05)$ than in those having combined palatoplasty and pharyngeal flap surgery. Hypoxaemia on arrival in the PAR was higher in children with surgical duration $>120$ min than if $<60 \mathrm{~min}$ (25.9\% vs $51.4 \%, P<0.05$ ). The incidences of early postoperative hypoxaemia in children $<3 \mathrm{yr}, 3-6 \mathrm{yr}$ and $>6 \mathrm{yr}$ were $54.2 \%, 41.9 \%$ and $34.4 \%$, respectively. There was a correlation between postoperative $\mathrm{SpO}_{2}$ levels and recovery scores: $\mathrm{SpO}_{2}(\%)=76.7+2.32 \times$ recovery scores, $\mathrm{r}=0.81, P<0.0001$. Children with

TABLE Pre-and postoperative $\mathrm{SpO}_{2}$ and the incidence of early postoperative hypoxaemia.

\begin{tabular}{|c|c|c|c|c|}
\hline & $\begin{array}{l}\mathrm{SpO} \\
(\%, \text { Mean } \pm S\end{array}$ & $\mathrm{SpO}_{2} 90 \%$ & $\begin{array}{l}\mathrm{SpO}_{2}=86-90 \% \\
\text { No. of children }\end{array}$ & $\begin{array}{l}\mathrm{SpO}_{2} 85 \% \\
\text { incidence (\%) }\end{array}$ \\
\hline Prcop & $98.8 \pm 0.9$ & $0(0)$ & $0(0)$ & $0(0)$ \\
\hline $0 \mathrm{~min}$ & $91.3 \pm 5.2^{\star}$ & $55(42.3)$ & $41(31.5)$ & $14(10.8)$ \\
\hline 5 & $91.7 \pm 4.3^{*}$ & $53(40.8)$ & $39(30.0)$ & $14(10.8)$ \\
\hline 10 & $92.0 \pm 4.3^{*}$ & $48(36.9)$ & $35(26.9)$ & $13(10.0)$ \\
\hline 15 & $92.4 \pm 5.3^{*}$ & $38(29.2)^{\star}$ & $28(21.5)$ & $10(7.7)$ \\
\hline 20 & $93.2 \pm 4.8^{\star}$ & $32(24.5)^{\star}$ & 25(19.2)\# & $7(5.4)$ \\
\hline 30 & $93.5 \pm 4.2^{\star}$ & $25(19.2) \#$ & $21(16.2) \#$ & $4(3.1) \#$ \\
\hline 40 & $94.3 \pm 5.2^{*}$ & $21(16.2) \#$ & 18(13.9)\# & $3(2.3) \#$ \\
\hline 50 & $95.0 \pm 4.2^{\star}$ & $14(10.8) \#$ & $11(8.5) \#$ & $3(2.3) \#$ \\
\hline 60 & $96.1 \pm 2.1^{*}$ & $6(4.6) \#$ & $5(3.9) \#$ & $1(0.8) \#$ \\
\hline 120 & $96.5 \pm 1.5^{\star}$ & $2(1.5) \#$ & $2(1.5) \#$ & $0(0)$ \\
\hline 180 & $96.8 \pm 1.2^{*}$ & $0(0)$ & $0(0)$ & $0(0)$ \\
\hline
\end{tabular}

$* P<0.01$ compared with preoperative $\mathrm{Sp}_{2}$.

$\# P<0.05$ compared with 0 min. low recovery scores (6) on arrival had a higher incidence of hypoxaemia than those with high recovery scores $(7-10)$.

Xue Fu-shan MD, Deng Xiao-ming MD, Liao Xu MD, Tong Si-yi MD, Liu Qing-hua MD, An Gang MD,

Luo Lai-kui MD

Beijing 100041

P.R. of China.

\section{REFERENCES}

1 Canet J, Ricos M, Vidal F. Early postoperative arterial oxygen desaturation. Determining factors and response to oxygen therapy. Anesth Analg 1989; 69: 207-12.

2 Soliman IE, Patel RI, Ebrenpreis MB, Hannallah RS. Recovery scores do not correlate with postoperative hypoxemia in children. Anesth Analg 1988; 67: 53-6.

\section{Upper airway obstruction complicating SLE}

To the Editor:

Systemic lupus erythematosus (SLE) is one of the immune-complex diseases characterised by organ damage related to the pathological deposition of immune complexes and consequent complement activation, and has a rare association with upper airway obstruction.

A 30-yr-old woman with SLE presented with a reduced level of consciousness grand mal seizures, hypertension and oedema of the face and neck. Control of the seizures and hypertension was achieved but inspiratory stridor developed and worsening facial swelling reduced the visibility of the oropharyngeal structures to a Mallampati class 3 view. ${ }^{1}$ It was decided to secure the airway by intubation. The oropharynx was anaesthetized with lidocaine $10 \%$ spray and the nasopharynx with cocaine paste and pre-oxygenation was administered. An Olympus LF-1 fibreoptic laryngoscope was passed through the nasal passages and glottis and general anaesthesia was induced. A tracheal tube was then railroaded over the bronchoscope into the trachea and its position confirmed. Mechanical ventilation continued until the patient's condition had improved.

Scarpelli et al. described a 21 -yr-old patient who had several admissions with manifestations of SLE, which settled with a therapeutic regimen of prednisone and aspirin. ${ }^{2} \mathrm{He}$ was finally admitted in a moribund state, deeply cyanosed and with marked facial oedema. Direct laryngoscopy revealed marked laryngeal oedema and intubation was unsuccessful, resulting in his death. Upper airway obstruction due to 
angioneurotic oedema is a rare but life-threatening complication of SLE. Flexible fibreoptic laryngoscopy allowed the atraumatic insertion of a nasotracheal tube and may be life-saving in this situation.

Richard Dell MB BS, FRCA

Department of Anaesthesia

Royal Cornwall Hospitals (Treliske)

Truro, Cornwall TRI 3LJ

Dr. Ann Marsh MB BS, MRCP, FRCA

Department of Anaesthesia

Lewisham Hospital NHS Trust

London SE13 6LH

\section{REFERENCES}

1 Mallampati SR, Gatt SP, Gugino LD, et al. A clinical sign to predict difficult tracheal intubation: a prospective study. Can Anaesth Soc J 1985; 32: 429-34.

2 Scarpelli DG, McCoy FW, Scott JK. Acute lupus erythematosus with laryngeal involvement. $\mathrm{N}$ Engl J Med $1959 ; 261: 691-4$.

\section{Erratum}

Correspondence: Predicting difficult laryngoscopy. R. Williamson. REPLY: D.K. Rose, M.M. Cohen. Can J. Anaesth 1996; 43: 1082

In the Reply from Drs. Rose and Coehn, the Table was inadvertently omitted and the third paragraph should read as follows:

For a similar patient population (May 1, 1995 to April 30, 1996), there were an additional 6,477 patients who had a direct laryngoscopy with attempted tracheal intubation following general anaesthesia. The rate of view of epiglottis only or no view of epiglottis was $1.5 \%$, 23 laryngoscopies $1.7 \%$, and failure to intubate $0.3 \%$. This rate of poor laryngoscopy view defined by our new criteria as Grade D or E was decreased from our previous study (10.1\%) but identical to the frequency reported in a prospective study by Wilson. ${ }^{1}$ As in our previous study, only a relatively small percentage $(26.3 \%)$ with view of only epiglottis or no view of epiglottis had $\geq 3$ laryngoscopies (previous study 15.8\%). However, for those patients with $\geq 3$ laryngoscopies, only $22.1 \%$ of those in the recent study compared with $84.1 \%$ previously had a view of only epiglottis or no epiglottis. The notation of best view on the record and the new grading system may have contributed to these reduced frequencies.

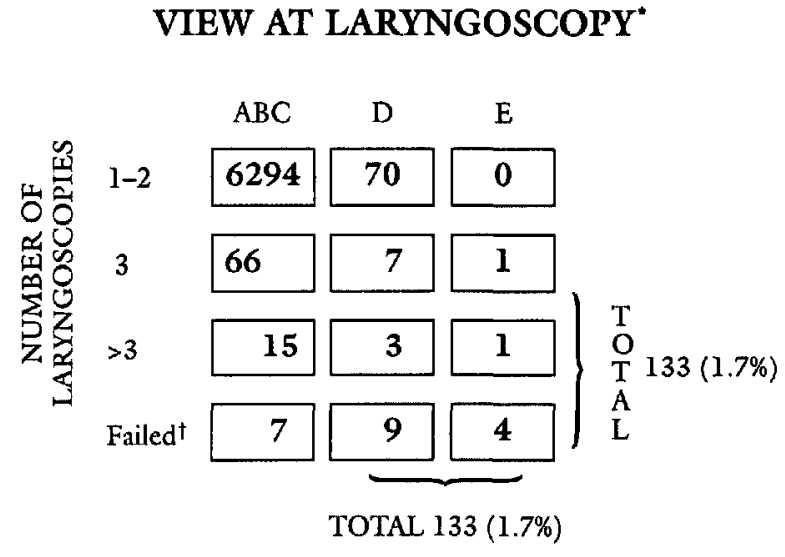

\footnotetext{
- Grade A: all of vocal cords, Grade B: partial view of cords, Grade C: arytenoids only, Grade D; epiglottis only,

Grade E: no view of epiglottis

$\dagger$ Failure of direcr laryngoscopy requiring alternative approach or cancellation
} 